\title{
Gender Differentials in Climate Change Perception in the Kaligandaki Basin, Nepal
}

\author{
Rishikesh Pandey
}

\begin{abstract}
Men and women variably perceive climate change, as the literature suggests that women perceive a higher level of changes compared to men. This study investigated differentials in climate change perception among Nepal's men and women, using a river basin level primary data. Data were collected from 360 household heads of three spatial clusters - Meghauli (153), Lumle (141), and Upper-Mustang (66), located at different ecological zones of the Kaligandaki Basin. Out of the total respondents, 106 were women. Perceptions on 11 weather-related elements were asked to the respondents to level the perceived change in the unipolar Likert Scale. Such information was supplemented through 75 Key Informants (KIs), 24 Focused Group Discussions (FGDs), and Historical Timeline Calendars from nine locations. Findings suggest that differences in climate change perception exist between women and men, and women in particular generally felt a higher level of change. However, the findings are not strongly supported by both statistical tests i.e. test of mean differences (the independent sample t-test) between the responses of men and women, and the test of association (chi-square) between the gender of respondents and the type of responses they have chosen. The findings indicate that both men and women perceive the change if it was easily noticeable. Therefore, a critical understanding of the association of other socio-economic and ecological factors on the construction of perception to climate change would be necessary to form a successful climate change adaptation policy. Furthermore, since the findings are based on an exploratory and cross-sectional study, further investigation with rigorous approaches is required to draw more concrete conclusions.
\end{abstract}

Keywords: climate change perception, gender, Himalaya, Kaligandaki Basin, Nepal

\section{Introduction}

The nexus between gender and environment is an established academic field of inquiry. However, gender connections to climate change have only been receiving the necessary attention recently. As a result, the Commission on the Status of Women (WHO, 2011) and the Intergovernmental Panel on Climate Change (IPCC, 2012) emphasized research on the climate change's gender dimension. Bhadwal, Sharma, Gorti, \& Sen (2019) accentuated to study of gender in climate change because they claim that existing social norms in relation to roles and responsibilities as well as entitlements and capabilities of women variably influence their perceptions to risk on the lives and livelihoods of the household. However, it is not only the gender but many intersections that are being neglected in policy responses, are the victims of contemporary environmental injustice that may lead them to perceive any changes variably than those of the privileged (Gay-Antaki, 2020).

Studies on climate change are dominated by technologically driven climate science. However, climatic warming, changing precipitation, and alteration in other weather elements are not only detected by climate science but also increasingly perceived by people. There are differences between the scientific and socio-cultural assessments of climate dynamics and the study of community perceptions is one of the important ways of understanding social constructions of change. The climate of a place is a product of interactions between natural and human systems and is understood through meteorological statistics and cultural interpretations (Hulme, 2008; Rayner, 2003). Scholars have investigated people's perceptions of climate and environmental changes in the Himalayas and Nepal (Chaudhary et al., 2011; Lazo, Kinnell \& Fisher, 2000; Manandhar et al., 2011). The assessment of community knowledge on climate and environmental change, also termed as 'citizen science' (Spellman, Field \& Sinclair, 2003), a form of science that relates to the concerns, interests, and activities of citizens as they go about their daily business, is increasing globally and also in Nepal. Poor communication of the findings of climate science to the people has increased the importance of studying climate change from a social or community perspective (O'Neill \& Hulme, 2009). Nevertheless, the perceptions of change vary across social-demographic, economic, and cultural backgrounds of people (Lazo, Kinnell \& Fisher, 2000; Rowe \& Wright, 2001; Sundblad, Biel \& Gärling, 2007). Perceptions also vary with personal epistemology and worldviews; climate politics, media and understanding of public debates on climate change (Bråten et al., 2009; Leiserowitz, 2005; Stedman, 2004); as well as the country of citizenship (stage of development); 
available amenities to respond to the climatic extremes; and the source of climate information (Hulme et al., 2009; Spellman et al., 2003). This paper elaborates, if 'gender' of respondents mattered in the perception of climate change.

\section{Climate Change Perception and Gender}

A bulk of the research on community perceptions to climate change reviewed here suggests that people from different parts of the world perceived increased frequencies and magnitudes of extreme events; warming in the winter and pre-monsoon periods; reduced winter rainfall; shifts in the monsoon season; increased variability in rainfall and extreme rainfall events (Devkota, 2014; Gentle \& Maraseni, 2012; Ghimire, Shivakoti \& Perret, 2010; Jones $\&$ Boyd, 2011). Research conducted in the Trans-Himalaya also showed increased avalanches, flash floods, erratic rainfall, and long and severe droughts (Fort, 2015; Vetås, 2007). Sujakhu et al. (2019) reported the vulnerability of female-headed households of disadvantaged social groups in the Melamchi watershed in Nepal because of their higher dependency on climate-sensitive livelihood resources and lower stock of alternatives resources. However, as the Himalayan environment is highly diverse, which makes it difficult to generalize not only the perception but also any form of information on natural or social systems, since the same climate of a place or two in reference to statistical descriptions may have quite different cultural assessments (Hulme et al., 2009). In such a context, Nepali Himalaya demands numerious and location-specific studies that are inhabited by different sections of the population, before making any generalization (Pandey \& Bardsley, 2013).

As community perception differs across the section of the population such as by gender, age, economic status, and occupation, this is indicative that men and women perceive the risk of disasters differently because of their familial productive, reproductive, and community roles and responsibilities as well as societal expectations of gender-specific performance. For instance, community people construct climate change perceptions based on the impacts they have experienced on their roles and responsibilities (Pandey, 2016a). Evidences show that women have a higher concern over environmental changes, probably due to their household and community roles that demand their closer connections to the natural environment and resources, they perceive higher risk than do men (Campbell, Bevc \& Picou, 2013; Flynn, Slovic \& Mertz, 1994; McClelland, Schulze \& Hurd, 1990; Stallen $\&$ Tomas, 1988). Since women of the Kaligandaki Basin experience a higher level of effects of climate change due to their closer connections to the natural environment and resources makes them capable of evaluating the impacts on livelihood resources carefully (Pandey, 2017), they might have been recognizing the change at higher intensity or as more serious than men. The variable social roles and responsibilities of women and men differ their degree of dependency on the natural environment, particularly on the livelihood resources, and women's higher concern over their status as a rarer and carer might creating such differences. However, a poor level of understanding of such knowledge risks inequitable policy-institutional systems would fail to prioritize women's need and exclude their engagement in climate change adaptation policy making, ultimately would increase the suffering of already marginalized women (Mersha \& van Laerhoven, 2019). Therefore, this work is to bring the issue to the forefront of policy discourse by further investigating the gendered aspect of climate change in Nepali and the Himalayan context.

Women are usually engaged in productive and reproductive roles within the household. Thus, they may be more concerned about changes in forest resources, watersheds, foreshores, and agricultural land, particularly in developing countries, which can have a severe effect on their ability to perform the daily household maintenance tasks (Röhr, 2007). Furthermore, gendered dimensions of climate change is not only the issue of women or female since the study of climate change in the gendered context is often dealt from a feminist perspective. The feminist perspective is a holistic approach that pays attention not only to women's lives and gendered structural constraints and opportunities but also equally concerns to the cultural symbols that promote inequalities across the intersections (Gurung-Goodrich, Udas \& Larrington-Spencer, 2019) and advocates for a hierarchy-less society for both policy and practice. In the Nepali context, women are directly responsible for fetching drinking water, collecting firewood, and fodder. They are also the ones to take care of farming and farm animals. Because of their direct connection with the environmental goods and services, they feel or observe any changes happening in their surroundings. The outcome is that as they find changing climate as one of the drivers altering their daily activities, they consider the change being serious. In other words, when women have to wait long to fetch water, they would feel prolong drought; or when they lose a number of working days due to the care burden of household members during a particular season, they would feel the weather pattern becoming unusual. However, men may not think those issues in the same way because of their detachment from those responsibilities. In such context, this paper brings the information of gender differentials, if any, in perception of climate change in the Himalayan environmental and social systems.

It is well documented that women and men differ with regard to their respective perceptions to climate and environmental change in a global context (Hasan \& Akhter, 2011; Huda, 2013; Ishaya \& Abaje, 2008). Poor level of understanding of gendered dimensions of perceptions on climate and environmental changes may compromise recognition of gendered needs in social and environmental management. This would undermine the adaptation process at first and then increase the vulnerability of women. While poor recognition of the severity of the change by men may lead to the formation of inappropriate or inadequate response policy, higher recognition of the alteration by women may lead to a chaotic policy. Therefore, understanding the situation from both women's and men's perspectives by selecting 
both genders as the sources of information and the units of analysis is obvious. Considering this fact, this paper analyses gender-dimension of climate change perception in the Kaligandaki Basin, Nepal.

This paper is divided into five sections. The first section introduced the issue of research by thoroughly exploring the status of knowledge in the field and identifying the gap. The second section conceptualizes gender, followed by the methods adopted in this research in the third section. The fourth section discusses the data and results of the study and finally, the last section offers the concluding remarks.

\section{Conceptualizing Gender}

Since the core theme of this study is to examine the gender dimensions of climate change perception, it is necessary to define the concept 'gender' at the outset. Although debated, 'gender' is a contested concept. It is contested because despite having over a half-century of discourse on 'gender' and advocacy for 'gender equity', the rationale of distinguishing the term 'gender', often considered as a social construction', from the term 'sex', a so-called 'biological category', has not been justified (Baden \& Goetz, 1998). A simple definition of gender is nothing more than a grammatical categorization of nouns in Indo-European languages. Many languages and cultures lack gendered connoted nouns while other cultures make distinction between productive and reproductive roles of individuals and those performing productive roles are considered as 'men' gender and of those engaged in reproductive roles are known as 'women' gender (Butler, 1999; Scott, 1989). Because of the adoption of productive and reproductive roles for a long period, sharp inequalities between the two genders has been observed globally, such as in Human Development (HDR, 2019) and gender distribution of assets (Gaddis, Lahoti \& Li, 2018). However, as productive roles undermined reproductive, that resulted in inferiority of women and the superiority of men in terms of access to and control over resources and decision making. This inequality engendered the movement for identity politics in the 1970s that advocated to bridge the gap between men and women, particularly in the access to and ownership of resources as well as in decision-making power. Nevertheless, socially expected roles and responsibilities, which are mostly taken as the basis of gender categorization, are 'context-specific' in that both genders perform cross-gender roles. Therefore, from a social perspective, there is no need of distinguishing men and women in the name of 'social construction.' Rather, the idea of binary categorization, even including the third category such as 'the third gender', is all about identity politics that seeks recognition of being different and advocate for not to be excluded and discriminated against based on gender identity.

In Nepal, 'gender' concept is often translated as 'women' into practice although, theoretical training in 'gender' particularly focuses on socially expected variable roles to be performed just because of being either male or female. The gender praxis emphasized access to and control over productive resources and decision-making, particularly political and administrative and the existing gendered-inequality in those fields justify the adoption of the concept synonyms to 'women.' Nevertheless, the concept of reproductive women and productive men is rapidly changing in the last decade and women are not limited only in the traditional gender roles (KC, Van Der Haar \& Hilhorst, 2017; Pandey, 2019a). Gender being an achieved or learned status (Lindsey, 2005), it is deeply rooted in Nepali societies, but variably because of diverse socio-economic and cultural diversity prevailing in the country. It refers that not in all of the societies of Nepal, but the majority have a belief system that privileges men over women so male dominance on to women's interest enacts and maintains the male supremacy. Gendering a child from early socialization by ascribing roles according to social norms and rules guide Nepali towards specific behavior in specific situations, which is hard to change. Therefore, women's gender are expected to be loving, nurturing, and caring. They are self-sacrifice for homemaking, while men gender as breadwinner. The ways of socialization that men acquire dynamics roles and power over the lifecycle and in different social contexts (Connell, 1994) have framed the men's gender in Nepal. Because of the better status of men in Nepali societies, women in Nepal give preference to male child (son) on the one hand and a higher number of men. Then, those of women are perpetrators of gender-based violence in Nepali societies (Nanda et al., 2012). Therefore, the gender advocates of Nepal focus on the integration and inclusion of women adopting an approach of identity politics.

Identity politics has created several genders that the traditional concept of 'gender' in terms of binary categories of men and women fails to address. The adoption of the third gender as an additional category in the recent past is also found to be inadequate. For example, popular social media Facebook lists 58 categories of 'gender' (Goldman, 2014; Oremus, 2014; Weber, 2014), even 71 categories for the UK users (The Telegraph UK, 2019). In such context, question emerges that how traditional categories such as 'women' and 'men', including the third gender, represent over 7.77 billion (as of the $7^{\text {th }}$ March 7, 2020 - https://populationmatters.org) population of the globe? And if gender identity is 'fun' of distinguishing oneself from others, why any ones' 'gender' is taken so seriously and considered as a matter of politics? Furthermore, if we need a binary category of humans, would not 'male' and 'female' be enough? Although either term male and female or men and women or even different in different language, could be used in binary category, all these ideologies makes the concept of 'gender' complex to understand and implement in policies. In other words, when the 'sex' differences can adequately demonstrate the existing inequalities between the two, and addressing those gap by promoting the interdependent relation of men and women through performance of "cross-gender roles' in a normal way is possible, there is no meaning of distinguishing 'gender' from 'sex', rather, both can be used as synonyms to each other (Pandey, 2019a). Or in other 
words, only one term either sex of gender could be enough. As the purpose of distinguishing between gender and sex was to emphasize the difference between biological and social sex, the 'sex' itself is a social construction (Baden \& Goetz, 1998) because it is the society that distinguish a baby either as a boy or a girl by birth (Butler, 1999).

The discussion above illustrates that sex or gender is the theoretical perspective of the division between male and female and is not as fixed and clear cut as once it was thought. It is so also because the 'sex' and 'gender' have distinct but overlapping biological and social identities. Nevertheless, despite the lack of reliable basis to justify inequalities between males and females biologically; it exists in households, communities, cultures, and in state mechanisms, and the historical, social, and cultural differences between women and men are often treated to convince that women's subordination being rational. Consequently, 'gender' has become synonyms to 'women' (Scott, 1989) and that is convincing the inferiority of women and the superiority of men in praxis.

The social expectation of gender varies with time, space, and technology and across communities, families, and individuals. Every individual has both masculine and feminine personalities indicating both genders within a person (Chodorow, 1978; 1995). It is the context that one gender is promoted over another and another gender lies in low profile until the context asks the person to engender the hidden gender. Consequently, gender can be a relational concept that agrees to the fact that the performance of cross-gender roles is normal (Alston, 2013) and everyone would exhibit relational gender. In addition to those claims, migration defies traditional gender roles (Pandey, 2019a) and over one-third of the population of the globe is on move, with over 271 million international migrants (UN, 2019), the socially constructed gender roles and expectations are not valid anymore. The same applies to technological advancement that has facilitated individuals to perform cross-gender roles successfully (Pandey, 2019b).

Social norms, values, behaviors, and customs form attitudes of individuals and construct an individual's thinking during their socialization. The socialization itself takes place in reference to one's 'sex', referring that the 'sex' is the primary basis of forming 'gender'. In such context, there are different tendencies - particularly two types of critiques in scholarly discourse, on the concept of gender that one is that using gender as synonyms to 'women' or as a binary category of men and women based on socially defined roles and responsibilities as well as expectation. This second approach of categorizing gender is particularly concerned with social stratification in relation to access to power and experience of marginalization, sometimes also included a 'third gender' for those who do not fit under 'men' and 'women' categories. Nevertheless, the socially constructed boundary or the demarcation of behaviors, customs, and attitudes to be shown by male or female is itself inappropriate because individuals inhibit such characteristics in relation to own cultural contexts. This definition indicates that gender has a crosscultural dimension so gender role, behavior, attitude, and expectations cannot agreed to be universal.

Since this research is an effort to create socially constructed knowledge on climate change using the understanding of both men and women on weather and climatic elements, gender and sex are used as overlapping concepts, or as synonyms to each other. It is also because of the fact that both men and women often perform crossgender roles and exhibit behaviors beyond their own gender, the concept hence has a contextual definition.

\section{Data and Methods ${ }^{1}$}

There are various ways of investigating women's and men's perceptions of climate change. Androcentric assumptions such as 'women's work are biologically determined and therefore is or should be home-based and restricted to nurturing and domestic chores' may devaluate women's knowledge on climate change. The norms of feminist empiricism have been constructed primarily to produce answers to the kinds of questions. This research interpreted the respondents' retorts on various 11 weatherrelated elements, and hearsay the stories of community people so the context-specific phenomena of gender and climate change could be seen.

The data for this study were collected from 360 households and community level interactions in several locations of three purposively sampled clusters located at different ecological zones of Kaligandaki Basin² (Figure 1). Different weather-related problems such as cold dryland (Upper-Mustang $^{3}$ ) in the Trans-Himalaya ${ }^{4}$, heavy rainfall regime (Lumle, Kaski) in the Middle-Mountains, and flood-prone area (Meghauli, Chitwan) in the Tarai were considered for purposive-area sampling. The data were collected under the author's PhD project (Pandey, 2016a) intending to investigate spatial-social (gender) variation in the perception of climate change. Therefore three different sites from the same drainage basin were purposively sampled considering their unique environmental and

1. The data and information utilized here were collected for the $\mathrm{Ph}$.D. research of the author. The gender issue could not been analyzed within the $\mathrm{PhD}$ project because the volume of the thesis exceeding the length prescribed by the institution. The collected raw data were analyzed in another project 'Gender Dimensions of Climate Change' in financial support of Pokhara University Research Centre (PURC). This paper is developed after further analyzing the data used in PURC Project so the information presented here may overlap with mentioned projects and other papers developed from the same.

2. Hot/wet below 300masl, Tarai; cool/wet temperate in between 1200-1800masl - Middle-Mountains; and cold/dry 30004000masl Trans-Himalaya

3. Upper Mustang (in terms of elevation, above 3000masl, and located within the Upper Kaligandaki catchment was selected purposively; though the term 'Upper Mustang' also regarded as 'Forbidden Kingdom' is different than the term used here. For instance, Muktinath and Zhong VDCs are not the part of 'Forbidden Kingdom'.

4. The Trans-Himalaya is sparsely populated so to make representative sample size, 5 VDCs (Muktinath, Zhong, Tsusang, Ghami, Tsaran) of Upper-Mustang (above 3000masl) were selected 
social situations. However, in the course of analysis, the gender components were dropped because of the length of analysis that was beyond the scope of the dissertation.

Figure 1: The Study Areas of Meghauli, Lumle and Upper-Mustang in Nepal

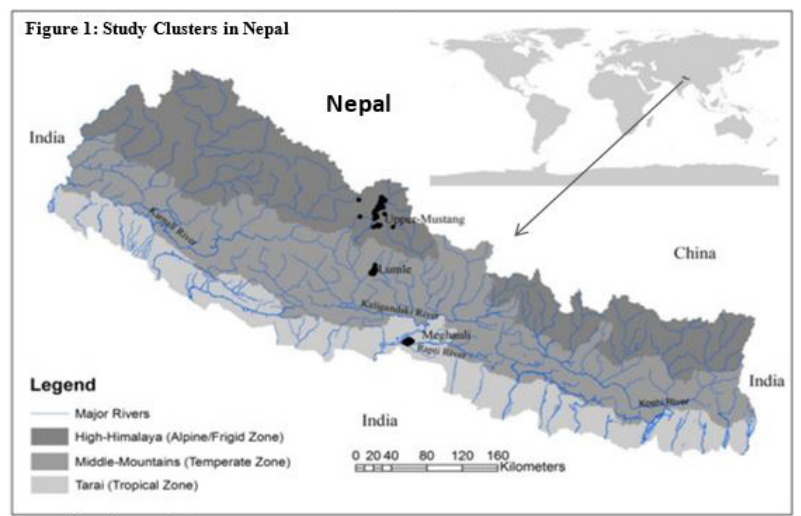

After purposive selection of Meghauli, Lumle and Upper-Mustang, 356 households were sampled using probability sampling method (out of 4849 households ${ }^{5}$ ) of 3 studied sites using error $€=0.05$ (5\% error), significance $=0.05(95 \%$ confidence level $)$, and estimated probability of success $(p)=50 \%$ values (Dixon \& Leach 1978, as cited by Kitchin \& Tate, 2000). The obtained samples were further divided into 3 study sites using proportional allocation, yet rounding the sample size. The final sample rested into 360 households with 153 households in Meghauli, followed by 141 and 66 households in Lumle and Upper-Mustang, respectively. The particular households were randomly selected from the lists of households available, and further consultation with the officials of local authorities. As the objective of the study is exploring the 'gender differentials', a comparable size of both men and women respondents was required. Nepali social practice often ignores reporting women as a household head although they work as a de-facto head. Since it was not possible to list the de-facto household heads, a strategy of controlling the third sample, if the initial two were males in each set of three samples, was adopted during the fieldwork to identify and obtain a de-facto women household head. By doing so, the final sample included $29.4 \%$ of women and $70.6 \%$ of men (Table 1 ).

Table 1: Number of Sampled Households by Place and Gender of Household Respondents

\begin{tabular}{|l|l|l|l|}
\hline Study Clusters & Women & Men & Total \\
\hline Meghauli & $47(30.7)$ & $106(69.3)$ & $153(42.5)$ \\
\hline Lumle & $40(28.4)$ & $101(71.6)$ & $141(39.2)$ \\
\hline Upper-Mustang & $19(28.8)$ & $47(71.2)$ & $66(18.3)$ \\
\hline Total & $\mathbf{1 0 6 ( 2 9 . 4 )}$ & $\mathbf{2 5 4}(\mathbf{7 0 . 6})$ & $\mathbf{3 6 0 ( 1 0 0 )}$ \\
\hline
\end{tabular}

Source: Field Survey, 2013

Note: Figures in the parenthesis denotes percent of

5. $\mathrm{N}=4894$ (Meghauli 3086, Lumle 1056, Mustang 752) (Ghami 169+Zhong 85+ Muktinath $198+$ Tsusan $168+$ Tsarang 132) in 2011 population census. respondents

Altogether 11 items related to weather variability in the last decade along with households' socio-economic characteristic, were asked to the head of household i.e. 106 women and 254 men, during the face-to-face interviews. Checklists on weather variability in the last four decades were discussed in 24 communities as focus group discussion, 75 key informants, and nine groups to construct Historical Timeline Calendar (HTC). The HTC is also a form of focus group discussion that is conducted particularly with senior citizens on the theme of extreme weather events and they would share their fragmented memories of the events and associated impacts. The questions and issues for questionnaire, FGD, KII, and HTC were fixed after an extensive review of literature, and piloting them in August-September, 2012, before finalizing them and administering in the field. The fieldwork was conducted from April to September 2013.

Unipolar Likert Scale was adapted to scale individual's perceptions of climate change. The scale ranges from 1 (the least change) to 5 (the most change).

Levels of responses (1 to 5) were later transformed into a single category to get the 'Normalized Responses' (Pandey, 2016a). This refers to that level of responses i.e. 1 to 5 , of different respondents is transformed to a single response level, and for all 11 items. The following formula was used to estimate the normalized level of response.

'Normalized Response $(\%)=($ Total score of actual response / Total of the highest possible score) $* 100$

Here, the 'Total score of actual response' refers to the cumulative score of a particular level of response from all the respondents (sum of number of respondent $*$ level of responses); the 'Total of highest possible score' denotes the total score of all the respondents if they have scaled their response to ' 5 ' in particular question (Total respondents multiplied by the highest score 5); whereas 100 is the 'constant' applied to calculate percentile.

The results were presented mostly in figures showing descriptive statistics. The means of level of response between men and women respondents were also tested using the student t-test (independent sample t-test) to explore the difference in the perception. The level of significance for both of the assessment was accepted to be a $95 \%$ confidence level. Furthermore, the test of association between the gender of respondents and the level of perceived change in particular weather elements was tested using the chi-square test.

Here, confusion may arise due to the adoption of multiple approaches of analysis. However, it become imperative, particularly due to the following reasons:

1. At first, only a single approach was applied to detect the gender differentials in the level of perception using the chi-square test. However, as the test of association does not detect remarkable differences, which was quite different than that of the general belief and as claimed in literature, another approach of testing the means was thought to be appropriate because it was suspected that poor association between gender and response categories might have been due to having many categories ( 5 class) of responses that reduced 
the concentration of responses.

2. t-test was performed since it was possible to transform the responses into a single response category providing an opportunity of reducing the dispersion of responses the responses collected using unipolar Liker scale was not possible to transform into two categories of 'yes/no' to increase the concentration of responses to obtain better chi-square test, but facilitate to treat the responses as 'scale' and transform that into total score to test the means.

3. By applying both approaches, results are validated further. Although there exist complexities in drawing conclusions through the results obtained from different approaches, particularly if there was variation in the results - one method showing significant differences while another not doing the same. Here, such results are explained as - differences in the test of means (significant $\mathrm{p}$-value of t-test) clearly justify the gender differentials in perception as the responses are concentrated (unified in single category of responses). However, if there was a significant association only between gender of respondents and the responsecategories (significant p-value of chi-square test), there is no significant variation in overall level of perception (both male and female feel the change) but not in the same way/same intensity).

\section{Results}

\section{Perception on Changes in Summer Temperature}

Peoples' perception on increased summer temperature in the Kaligandaki Basin indicated that over four-fifths respondents, with almost $90 \%$ in terms of 'normalized response', recognized increased warming in summer (Figure 2a). The data indicate a small variation in the responses between women $(91.3 \%)$ and men $(82.2 \%)$ respondents (normalized proportion) who have reported an increase in summer temperature. Among the total, $73.1 \%$ women felt a increased summer temperature, which is notably higher than that of the proportion of men i.e. $61.3 \%$. The community perception obtained from FGD, including HTC, also supports the individual's perception that summer temperature in all of the three study locations is changing, particularly, increasing. The finding shows women's higher level of risk perception compared to men, and it is consistent with literature (Campbell et al., 2013; Flynn et al., 1994; McClelland et al., 1990; Stallen \& Tomas, 1988). This difference is statistically significant while comparing the means of responses of men and women respondents since the $\mathrm{p}$-value of the $\mathrm{t}$-test is 0.012 (equal variance assumed). Nevertheless, there is no statistically significant association between the gender of respondents and the level of responses (5 categories of responses) as the p-value of the chi-square test is greater than 0.5 i.e. 0.177 (Table 2). The significant difference in the means indicate that women or men, both as different but being the intra-homogenous groups, variably perceived the changes in summer temperature although that is not consistent or applicable to all the sub-groups across the gender and response categories or the intensity of change (the least to the highest level of response category 1 to 5). This finding can be referred to as - despite having gender differentials in overall perception in the change in summer temperature, men and women perceive the intensity of change in the same way, and it might be due to a high level of change.

\section{Perceptions on Changes of Winter-Summer Temperature Range}

A change in altered temperature is one of the indicators of local climatic dynamism. Over three-fourths of respondents reported an increase in temperature range, i.e. an increased difference between the average of summer and winter temperatures in the Kaligandaki Basin (Figure 2a). The gender-specific response in the issue illustrates that slightly higher proportions of women $(87.5 \%)$ as compared to $79.4 \%$ of men reported an increase in temperature ranges. In specific, $58.7 \%$ of women reported a widened range of annual minimum and maximum temperatures while the proportion of men having a similar perception is $47.9 \%$. Key informants and the community people participated in the FGDs collectively reported that the winters are harsher, but only for a short period, while summers are even hotter. Despite a little difference in the normalized proportion of responses ( $86.1 \%$ for women and $80.8 \%$ for men), the means of responses are significantly different between them since the $\mathrm{p}$-value of the t-test is 0.019 . The chi-square test result, however, does not show consistent results to the t-test statistics since there is no significant association between the gender of respondents and the level of response or response categories ( $p$ 0.108). These findings inform us the presence of gender-based differences in the overall perception of change in temperature range but not all respondents feel it at the same intensity. In other words, both men and women perceive changes in fairly same intensity although there is a significant difference in the overall perception of change in temperature range.

\section{Perception on Winter Temperature}

The majority of respondents $(72 \%)$ of the Kaligandaki Basin reported an increase in winter temperature (Figure $2 \mathrm{a})$. Since there is no notable difference in the proportion of normalized responses of women $(86.1 \%)$ and men $(81.3 \%)$ in relation to reporting 'increased winter temperature'; we tested the difference in the means of perceived level of response using the student's t-test. This difference, however, is not statistically significant $(p$-value $=0.787)$. Also, there is no significant association $(p=0.343)$ between the gender of respondents and the level of perception on increased winter temperature (Table 2). The participants of the FGDs, irrespective of gender identity, further explained the warming in the winters that the length of the winters is reduced as spring season arrives early and summer lasts longer. Nevertheless, they also claimed that extreme minimum temperature in winter dropped down further making it harsh, although only for a short period 
of time. The informants gathered in FGD also reported increased numbers of snow-free winters in the parts of Middle-Mountains and the Trans-Himalaya.

\section{Perception on Decreased Annual Rainy Days}

The change in rainfall pattern is also reported by quite a high proportion of respondents of the Kaligandaki Basin (Figure 2a). Of the total, little over three-fourths of the respondents stated decreased annual rainy days although there is no remarkable difference between the normalized proportions of women $(82.6 \%)$ and men (80.2) respondents who have reported a decrease in annual rainy days. The t-test also indicates no significant differences in the means of the level of responses of men and women respondents ( $p$ value $=0.628$ ), although the proportion of respondents expressing a decreased annual rainy days is higher for women (51\%) comparing to those of men (39.4\%). This visible difference is also justified by the test of association between gender of respondents and the perceived intensity of decrease in annual rainy days (response categories) as the p-value of the chi-square test is 0.001 (Table 2). These variable findings (in independent sample t-test and test of association) indicate that although men and women perceive the intensity of 'decrease in annual rainy days' differently, the overall or cumulative perception is not significantly different as exhibited by t-test. It is probably because of variations in perceiving the intensity of change rather than the only one to change.

\section{Perception on Decreased Winter Rainfall}

A majority $(81.3 \%)$ of the respondents of the Kaligandaki Basin reported decreased winter rainfall (Figure 2a). There is quite a little variation in the normalized proportion of response by gender of respondents (women: $83.7 \%$ and men: $79.5 \%$ ); although a major difference in the proportion of women $(53 \%)$ and men $(42.3 \%)$ respondents is visible in the choice of response option 'clearly observed the decrease'. The result indicates no significant difference in the means of men's and women's response level $(\mathrm{p}$ value $=0.156)$. This is consistent with the chi-square test result too, that there is no statistically significant association between the gender of respondents and the level of response as the p-value is 0.360 (Table 2 ). The community people who participated in the FGD also reported that winter rainfall is decreased as it has been shifted to spring season, particularly in the TransHimalaya and Middle-Mountain. The Tarai lacks spring rains. These community observations also support the result of the analysis of individuals' perceptions that lack gender differential.

\section{Perception on Erratic Rainfall Events in Monsoon}

Several scientific studies reported changing behavior of monsoon and it has become variable, uncertain, and violent in South Asia and Nepal (Pandey, 2016b; Nepal, 2012; Turner \& Annamalai, 2012; Shah \& Lele, 2011).
The respondents of the Kaligandaki Basin also reported 'increased erratic monsoon rainfall' (Figure 2a). A total of $85.2 \%$ of respondents, with the normalized proportions of $78.7 \%$, reported the increase in erratic rainfall events which matches with perception of the FGD and HTC participants. Across the gender, $83.2 \%$ women, and $76.8 \%$ men perceived such change although the test of means demonstrates no differences in perception by gender of respondents at $95 \%$ confidence level as the p-value of t-test is 0.068 . A remarkable variation in the proportion of women and men respondents who reported 'clearly increase erratic rainfall events' is observed as $55.8 \%$ women followed by $41.9 \%$ men have chosen the option. However, the statistical test identifies no significant association $(p=0.196)$ between the gender of respondents and the level of perceived change in erratic monsoon rainfall (Table 2). It reflects that the erratic rainfall events in monsoon are common in the Kaligandaki Basin and the perception of both men and women to it is indifferent.

\section{Perception on Summer Floods}

As the monsoon rainfall has become erratic in the basin, monsoon floods have also become frequent and intense. Almost all the participants of FGD and HTC reported the increased frequency and intensity of summer floods, in all of the three study sites. It is evident from Figure $2 b$ that over three-fourths of individual respondents also perceived such an increase. There is a little difference in the normalized proportion of women (76.4\%) and men (72.5\%) who reported the increase in frequency and intensity of summer floods. The variation in the proportions of women $(41.3 \%)$ and men $(31.2 \%)$ reporting the change at the intensity of a 'clearly increased frequency and intensity of summer floods' is seen despite statistical observation does not show a significant difference in the means of the level of responses since the p-value of the t-test is 0.209 . Furthermore, there is no significant association between the level of responses to 'increased summer floods' and gender of responses since the $\mathrm{p}$-value of the chi-square test is 0.150 (Table 2) reflecting the lack of gender differential in perceiving summer floods.

\section{Perception on Changes in the Seasons of Hailstorm}

Figure $2 \mathrm{~b}$ presents the response of the research participants on 'occurrence of hailstones'. The participants of the group discussion reported that the occurrence of hails has been becoming unpredictable over seasons in recent years and is occurring in off-seasons (other than spring and autumn) as well. The sampled respondents were asked to rate the intensity of such change. A total of $70.9 \%$ respondents, with $76 \%$ of women and $68.8 \%$ of men, reported some changes in occurrence and seasonal uncertainty in hailstone occurrence. The normalized responses show over two-thirds of respondents perceiving the changes and of the total, about $18 \%$ reported a clear change while $35.6 \%$ often have felt the changes. There is a little variation in the proportion of women $(68.1 \%)$ and 
Figure 2a: Perception on various Weather Elements in the Kaligandaki Basin, Nepal by Gender (Source: Field Survey 2013)

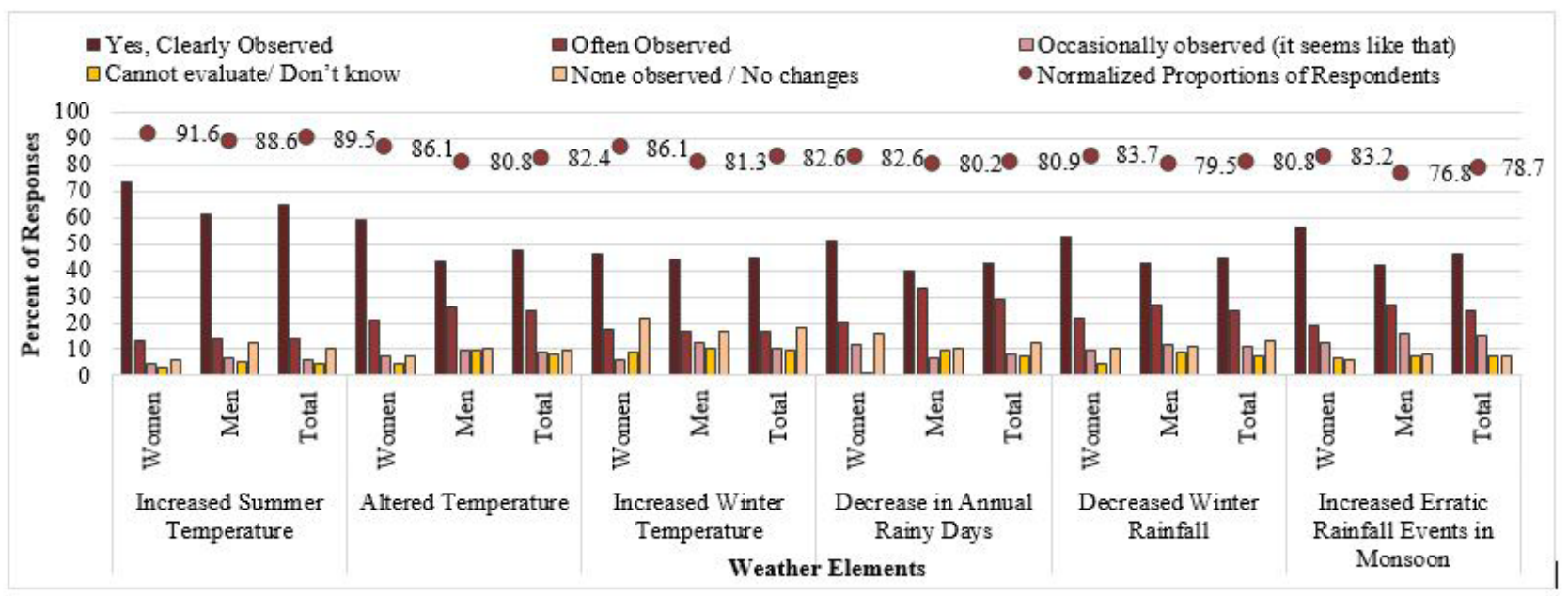

men $(64.3 \%)$ who reported the 'change in seasons with hailstones'. However, this change is not justified by both of the statistical tests i.e. the test of differences in means using independent t-test since the p-value is 0.227 ; and the test of association between the gender of respondents and the perceived level of change since $p$-value of the test of association is 0.517 (Table 2).

\section{Perception on Changes in Intensity and Frequency of Drought}

Figure $2 \mathrm{~b}$ shows the perception of respondents on 'change in intensity and frequency of drought' in the Kaligandaki Basin. According to the respondents, drought in the basin is becoming frequent and intense that almost $90 \%$ of respondents with a normalised response of $85 \%$, perceived increased frequency and intensity of drought. In particular, almost $60 \%$ respondents felt a 'clearly increased drought' and the other $21 \%$ 'often felt' such change. There is a little variation in the normalized proportion of response across the gender identity of respondents that $86.8 \%$ of women followed by $84.3 \%$ of men perceived the change. However, this difference is not statistically significant since the p-value of the test of means of the level of response is 0.172 . The proportion of women respondents who identified a 'clearly increased frequency and intensity of drought' is $62.5 \%$ against of $57.7 \%$ men. However, the association between the gender of respondents and the corresponding response on drought is not statistically significant since the $\mathrm{p}$-value of the chi-square test is 0.549 (Table 2).

\section{Perception on Change in Onset and Retreat of Summer Monsoon}

With the course of climate change, characteristic of summer monsoon has also been changed and community people, including individual respondents, have perceived such alteration (Figure 2b). Of the total, over twothirds of the studied population reported changed onset and retreat of the summer monsoon. The normalized proportion of respondents reporting such change is even higher i.e. $76.3 \%$. There is no notable difference between the normalized proportion of women $(79.7 \%)$ and men (74.9\%) reporting the change but the difference is not justified by the t-test result since the p-value is 0.709 at $95 \%$ confidence level. However, variation is evident in the proportion of respondents reporting specific intensity of change such as 'clearly observed change.' While $35.3 \%$ of the respondents have perceived a 'clear change' in arrival and retreat of summer monsoon, more women (40.4\%) than that of men $(33.2 \%)$ have chosen the response option. The chi-square test of association between the gender of respondents and the level of perception on change in 'arrival and retreat of summer monsoon' is significant since the p-value is 0.015 (Table 2). Here, gender is associated with the level of perceived intensity of change than the mere change only. In other words, as the change in onset and retreat of the summer monsoon is well experienced by both men and women respondents, but the intensity of change is variable with the gender of respondents.

\section{Perception on Increased Incidents of Violent Wind}

Figure $2 \mathrm{~b}$ presents responses to increased incidents of violent wind in the Kaligandaki Basin. Over fourfifths of respondents, with the normalized proportion of $73 \%$ respondents, reported the increase in violent wind. Among the total, $31.7 \%$ have observed a 'clearly increased incidents' while the other $32.8 \%$ 'often felt' such change. There is a little variation in the perception of respondents across the gender that a higher proportion of women $(84.6 \%)$ against $79.1 \%$ men perceived an increase in the incidents of violent wind. The normalized response, however, came to be $76.9 \%$ for women and $71.3 \%$ for men and the test of means also shows a significant difference at $95 \%$ confidence level as the p-value is 0.041 reflecting the fact that women and men variably perceive the increase in violent wind. However, despite the significant difference in means of responses and visible variation in the proportion of women $(41.3 \%)$ and men $(27.7 \%)$ selecting specific response category i.e. 'clear increase in the incidents of 
Figure 2b: Perception on various Weather Elements in the Kaligandaki Basin, Nepal by the Gender of Respondents

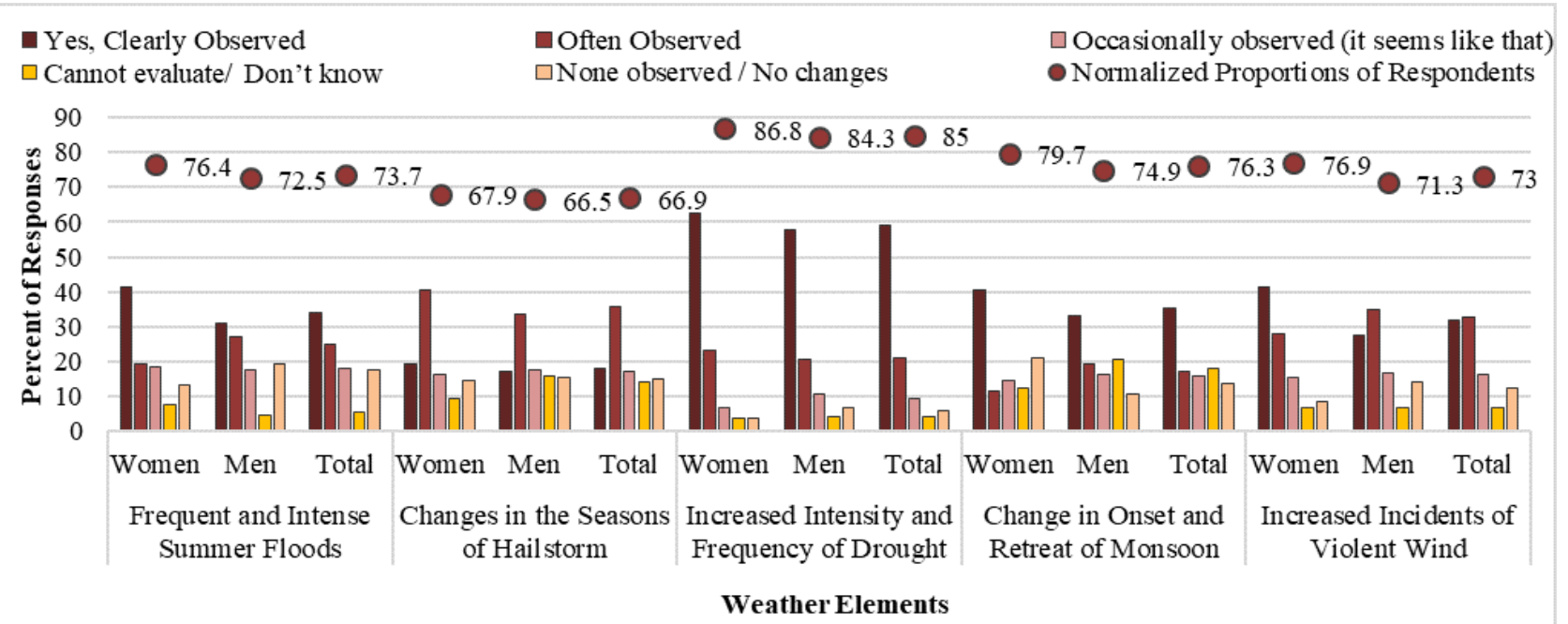

Table 2: The test of Means and an Assessment of Association between Level of Perceived Changes in Climate System with Gender of Respondents in the Kaligandaki Basin, Nepal

\begin{tabular}{|l|l|l|}
\hline $\begin{array}{l}\text { Perception on } \\
\text { Weather Ele- } \\
\text { ments /Variables } \\
\text { by Gender of } \\
\text { Respondents }\end{array}$ & $\begin{array}{l}\text { p-value of the Test of } \\
\text { difference in Means } \\
\text { (independent sample } \\
\text { t-test) of Responses by } \\
\text { gender of respondents }\end{array}$ & $\begin{array}{l}\text { Association } \\
\text { of Percep- } \\
\text { tion with } \\
\text { (Pearson } \\
\text { Chi-square } \\
\text { p-value) }\end{array}$ \\
\hline $\begin{array}{l}\text { Increased Summer } \\
\text { Temperature }\end{array}$ & 0.012 & 0.177 \\
\hline $\begin{array}{l}\text { Altered Tempera- } \\
\text { ture/Inc re a s d } \\
\text { Range of Max - } \\
\text { Min Temperature }\end{array}$ & 0.019 & 0.108 \\
\hline $\begin{array}{l}\text { Increased Winter } \\
\text { Temperature }\end{array}$ & 0.787 & 0.343 \\
\hline $\begin{array}{l}\text { Annual Rainy Day } \\
\text { Decreased }\end{array}$ & 0.356 & 0.001 \\
\hline $\begin{array}{l}\text { Winter Rain De- } \\
\text { creased }\end{array}$ & 0.156 & 0.360 \\
\hline $\begin{array}{l}\text { Increased Erratic } \\
\text { Monsoon Rain }\end{array}$ & 0.068 & 0.196 \\
\hline $\begin{array}{l}\text { Frequent and In- } \\
\text { tense Monsoon } \\
\text { Floods }\end{array}$ & 0.209 & 0.150 \\
\hline $\begin{array}{l}\text { Changes Season in } \\
\text { Hailstone Occur- } \\
\text { rence }\end{array}$ & 0.227 & 0.015 \\
\hline $\begin{array}{l}\text { Increased Fre- } \\
\text { quency and Inten- } \\
\text { sity of Drought }\end{array}$ & 0.172 & \\
\hline $\begin{array}{l}\text { Arrival and With- } \\
\text { draw of Monsoon } \\
\text { Changed }\end{array}$ & 0.709 & \\
\hline $\begin{array}{l}\text { Increased Inci- } \\
\text { dents of Violent } \\
\text { Wind }\end{array}$ & 0.041 & \\
\hline
\end{tabular}

Note: The association experimented between gender of respondents and their corresponding responses on different weather elements in the Likert Scale (1-5 Scale) using Cross Tabulation Chi-Squire Test in SPSS. The $\mathrm{p}$ values of significant associations inform 'significant difference between the perception of men and women respondents' while no association (not significant $\mathrm{p}$ values) indicates 'no differences in perception of men and women respondents.' or in other words, gender does not matter in climate change perception.

violent wind'; there is no statistically significant association between the gender of respondents and the response categories or perceived because the p-value of the test of association is 0.120 (Table 2). This sort of variability between the result of the test of means (t-test) and the test of association (chi-square) suggests that women and men, as two homogenous groups, have variably seen the increase in the incident of violent wind in general, but their representation into different response categories do not correspond the same, strengthening the fact that despite having gender differentials in overall experience, men and women perceive the intensity of change in the same way.

Table 2 presents statistics of the test of means (independent sample t-test) and the test of association (chisquare) results performed between gender of respondents and the response categories they have selected in various weather elements discussed above. Table 2 shows five variables, of which, perceptions of men and women are significantly different in either ways i.e. test of means ('Increased Summer Temperature', 'Altered Temperature', and 'Increased Incidents of Violent Wind') or the test of association ('Annual Rainy Day Decreased' and 'Arrival and Withdraw of Monsoon Changed') while perception to the rest of six variables do not show any gendered variations. This indicates that the climate change perception is partially variable across the gender.

Afore section has extensively discussed the results of the study of community perception on various weather elements from gender perspectives, which collectively indicate that the climate of the Kaligandaki Basin is changing. While a higher proportion of women reporting higher levels of change is identified in almost all of the eleven weather-related variables than that of men although 
many lack of significant association between the gender of respondents and the level of responses. From the findings discussed above, it is generally understood that women respondents tend to perceive more intense changes in weather elements than those of men. However, the lack of a significant association between gender and level of response helps draw the conclusion that gender does not necessarily influence the perception on climate change. It is probably so because as there is a high level of alteration in the climate system, which men also cannot ignore. Nevertheless, women are more likely to perceive a higher level of change compared to men. It is probably associated with other socio-economic factors of households that need further analysis. In general, community people living in the same cluster for a long time and been engaged in a similar occupation such as agriculture, seemingly perceive the changes in climate system fairly same way so 'gender' as a binary category of women and men does not significantly matter in the construction of climate change knowledge at community level.

\section{Conclusions}

This research was conducted in the Kaligandaki Basin, Central Nepal. Research was based on primary data collected in 2013. Household survey-interviews complemented by HTC, FGD, KIIs, and observation tools were applied to collect information. Descriptive statistics is produced and a test of associations was performed between the gender of respondents and their opinions on various weather-related variables. Research evidences, including this one, have illustrated major alteration in climate systems of the Kaligandaki Basin, Nepal. Understanding climate change from community perception has been becoming an important methodology as the perception can be variable in reference to culture, gender, economic class, and occupation of respondents as well as state of local physical environment. As this research analyzed community perception on carefully selected 11 weatherrelated variables by comparing the response of the gender of informants, here 'gender' is adopted as a relational concept that demands for empirical findings (Harding, 1987).

This study failed to detect a significant association between the gender of respondents and their perceived level of change in most of the weather-elements and the same applies to the test of means. However, out of the 11 variables analyzed, perception on five variables shows gendered variations by either approaches i.e. test of means or the test of association. This indicates that gender is not a strongly associated factor of constructing perception on climate change, but it warrants to be considered while crafting response policies since several variables show gendered differentials in climate change perceptions. The limited variations in response by gender might be associated with a higher level of changes that everyone can easily notice. The respondents represented fairly homogenous occupation (agro-livestock) with owning a small plot of land, might have produced homogenous perception although, this requires further analysis. In addition to that women-headed households are performing a cross-gender role or they are leading or managing the household from a masculine perspective in the study area (Pandey, 2019a), their perception on climate change is not only representing 'women' gender per se. In other words, consistent with the Chodorow's (1978; 1995) notion, women of the Kaligandaki Basin find it hard to distinguish their own needs from the needs of those around them (households) because women do not individuate themselves, their perception to climate change is not independent to the general communication and community interactions. The consequence is that this study detected a significant association between gender of respondents and level of perceived changes only in few cases such as in 'decreased annual rainy days' $(\mathrm{p}=0.001)$ and 'changed onset and retreat of summer monsoon' $(p=0.015)$ and differences in the means in other three variables such as 'Increased Summer Temperature', 'Altered Temperature', and 'Increased Incidents of Violent Wind'. Although there exist complexities in drawing conclusions through the results obtained from different approaches, the significant differences in the test of means justify the gender differentials in perception while the significant association between gender of respondents and the response-categories indicate variation in the perception in intensity but not an overall change. These findings, in general, indicate that women perceive a higher level of change (as the majority of variables have a higher level of normalized proportion of women than men reported the change) and that might be due to their higher concern over the welfare of their partner, children and livelihood resources. The adoption of multiple approaches here is important because the findings of this work are not consistent with the conventional belief that 'women' perceive higher risk than that of men, which is not always correct.

This study tried to negotiate three concepts of gender: gender as 'men and women', gender as 'masculine and feminine attitudes and behavior (cross-gender roles)', and gender as 'women' by providing information and explanations despite the analysis and presentation of data seem to be 'gender' as a binary categorization of men and women. Gender as behaviors, customs, and attitudes or feminine and masculine personalities is elaborated from the information on cross-gender activities performed by either gender (Pandey, 2019a). In addition, gender as 'politics of the power relations and strategy for negotiation by advocating to bridge the gender-based inequalities' is justified by looking to the inequalities between men and women-headed households (Pandey, 2017). On the other hand, as women are at the bottom of power-relations in the sense of access to productive assets and decision-making, it is not odd to understand 'gender' as 'women' (Deere \& Doss, 2008; Gaddis, Lahoti \& Li, 2018; Nader, 1986; Ruel \& Hauser 2013; UNDP/HDR, 2019). Based on the above analysis, this research made the following concluding statements:

- Community people have sound knowledge of climate change. Therefore policy intervention to respond to 
climate change should consult social understanding of change with scientific results and trends. As GayAntaki (2020) stressed, a critical mass of women with clear and in-depth knowledge of climate change will automatically generate gender-friendly climate policies.

- Because of a number of cross-gender roles being played by Nepali women, their traditional genderidentity as 'women' is gradually eliminated by climate change and migration of adult men from households (Pandey, 2019a). The homogeneity in occupation might have also played role in weakening gendered variation in perception. It reflects that women of the Kaligandaki are performing reproductive, productive, and community roles at a time, and that have implicated into the construction of climate change knowledge. Such construction might have played a role in narrowing the differences in understanding of climate change by men and women, although the adopted method of analysis may not be adequate to detect 'gendered' differentials, warranting for adoption of more robust methodologies.

Although study of climate change perception is one of the important ways to understand the socially constructed knowledge of change and associated risks, literature informed that the perceptions vary across the socialdemography and economic and cultural background of population and geographic environment (Lazo et al., 2000; Rowe \& Wright, 2002; Sundblad et al., 2007). However, as this paper could not include all those elements in the analysis because of its length, further analysis of data to explore the factors associated with perception on climate change is required.

\section{Acknowledgments}

I owe a lot to the communities of Meghauli, Lumle, and Upper-Mustang for their time given during data collection. Thanks are due to Kamal Sing Thapa, Dharma Raj Parajuli, Deependra Pandit, and Pawan Chitrakar, who have assisted me in my tough fieldwork. I am thankful to Pokhara University Research Centre (PURC), Pokhara University, Nepal, where this part of analysis is assisted financially under Faculty Research Grant No: 03/2072/73. The data were collected under different project (Author's $\mathrm{PhD}$ ), which was conducted at the University of Adelaide, Australia and was supervised by Dr. Douglas K Bardsley and Dr. Dianne Rudd. I would also like to thank the peer reviewers of the manuscript and the Journal Editors for their generous feedback.

\section{Funding}

The data were collected under Author's Ph.D. project at the University of Adelaide, Australia under International Postgraduate Research Scholarship (IPRS) and fieldwork was supported by Research-Abroad Scholarship of the same institution. Pokhara University Research Centre (PURC), Pokhara University, Nepal has provided a small research grant to conduct research in 'Gender dimensions of climate change' under Faculty Research Grant No: 03/2072/73, from which, this manuscript is developed.

\section{Ethics Approval and Consent to Participate}

This paper 'Gender Differentials in Climate Change Perception in the Kaligandaki Basin, Nepal' involves human participants and human data. The data have been collected for the Author's Ph. D. project, and data have been collected through informed consent. Written consent from all the research-participants have been obtained prior to starting the conversation (after the thorough greetings and introducing the prospective participants to the purpose of the research). This research followed all the ethical concerns by adopting the National Statement on Ethical Conduct in Human Research and the Australian Code for the Responsible Conduct of Research. The research obtained ethical approval from the Research Ethics Committee of South Australia (a joint committee of the University of Adelaide, University of South Australia, and Flinders University, Australia) with the Approval Number HP-2012-046.

\section{Consent for Publication}

'Not applicable' as there is no personal information of the persons included in the manuscript.

\section{Availability of Data and Materials}

All the data required for the manuscript have been included in the paper. The data are being used for further analysis in different themes as they were collected for a bigger project, they are not been made available publicly at this point of time. However, as all the raw data are stored in SPSS format, they may be made available on special request, with adequate justification of the need of the data.

\section{Competing Interests}

There is no competing interest with any individual and agencies.

\section{Reference}

Alston, M. (2015). Women and climate change in Bangladesh, Routledge.

Baden, S., \& Goetz, A. (1998). Who needs [sex] when you can have [gender]: Conflicting discourses on Gender at Beijing. In C. Jackson \& R. Pearson (eds.), Feminist Visions of Development: Gender Analysis and Policy. Routledge.

Bhadwal, S., Sharma, G., Gorti, G., \& Sen, S. M. (2019). Livelihoods, gender, and climate change in the Eastern Himalayas. Environmental Development. 31, 68-77, https://www.10.1016/j.envdev.2019.04.008

Bråten, I., Gil, L., Strømsø, H. I., \& Vidal-Abarca, E. (2009). Personal epistemology across cultures: Exploring Norwegian and Spanish university students' epistemic beliefs about climate change. Social 
Psychology of Education. 12(4), 529-560, https://doi. org/10.1007/s11218-009-9097-z.

Butler, J. (1999). Gender Trouble (2nd eds), Routledge.

Campbell, N. M., Bevc, C. A., \& Picou, J. S. (2013). Perceptions of toxic exposure: Considering "white male" and "black female" effects'. Sociological Spectrum. 33(4), 313-328, https://doi.org/10.1080/027 32173.2013.732882.

Chaudhary, P., Rai, S., Wangdi, S., Mao, A., Rehman, N., Chettri, S., \& Bawa, K. (2011). Consistency of local perceptions of climate change in the Kangchenjunga Himalaya landscape. Current Science, 101(4), 504-513. Retrieved 19 November, 2020, from http://www.jstor.org/ stable $/ 24078981$

Chodorow, N. (1978). Reproducing Mothering, University of California Press.

Chodorow, N. (1995). Family structure and feminine personality. In N. Tuana \& R. Tong (eds.) Feminism and Philosophy, Boulder, CO, Westview Press.

Connell. R. W. (1994). Masculinities. University of California Press.

Deere, C. D., \& Doss, C. R. (2008). The gender asset gap: What do we know and why does it matter? Feminist Economics. 12(1-2), 1-50, https://doi. org/10.1080/13545700500508056.

Devkota, R. P. (2014). Climate change: Trends and people's perception in Nepal. Journal of Environmental Protection, 5, 255-265, https://doi.org/10.4236/ jep.2014.54029.

Flynn, J., Slovic, P., \& Mertz, C. K. (1994). Gender, race, and perception of environmental health risks. Risk Analysis, 14(6), 1101-1108, https://doi. org/10.1111/j.1539-6924.1994.tb00082.x.

Fort, M. (2015). Natural hazards versus climate change and their potential impacts in the dry, northern Himalayas: Focus on the upper Kali Gandaki (Mustang District, Nepal). Environmental Earth Sciences, 73(2), 801814, https://doi.org/10.1007/s12665-014-3087-y.

Gaddis, I., Lahoti, R., \& Li, W. (2018). Gender gaps in property ownership in Sub-Saharan Africa. Policy Research Working Paper 8573. World Bank Group, Gender Global Theme.

Gay-Antaki, M. (2020). Feminist geographies of climate change: Negotiating gender at climate talks. Geoforum, 115, 1-110, https://doi.org/10.1016/j. geoforum.2020.06.012

Gentle, P., \& Maraseni, T. N. (2012). Climate change, poverty and livelihoods: Adaptation practices by rural mountain communities in Nepal. Environmental Science \& Policy, 21, 24-34, https://doi.org/10.1016/j. envsci.2012.03.007.

Ghimire, Y. N., Shivakoti, G. P., \& Perret, S. R. (2010). Household-level vulnerability to drought in hill agriculture of Nepal: implications for adaptation planning. International Journal of Sustainable Development \& World Ecology, 17(3), 225-230, https://doi.org/10.1080/13504501003737500.

Goldman, R. (February 13, 2014). Here's a List of 58 Gender Options for Facebook Users. Retrived 07 March 2020 from https://abcnews.go.com/blogs/ headlines/2014/02/heres-a-list-of-58-gender-optionsfor-facebook-users.

Gurung-Goodrich, C., Udas, P. B., \& Larrington-Spencer, H. (2019). Conceptualizing gendered vulnerability to climate change in the Hindu Kush Himalaya: Contextual conditions and drivers of change. Environmental Development, 31, 9-18, https://doi. org/10.1016/j.envdev.2018.11.003

Harding, S. (1987). Introduction: Is there a feminist method?' In S. Harding (eds.), Feminism and methodology: social science issues. Indiana University Press, USA. 114.

Hasan, Z., \& Akhter, S. (2011). Determinants of public awareness and attitudes on climate change in urban Bangladesh: Dhaka as a case. European Journal of Social Sciences, 21(1), 154-162.

Huda, M. N. (2013). Understanding indigenous people's perception on climate change and climatic hazards: A case study of Chakma indigenous communities in Rangamati Sadar Upazila of Rangamati District, Bangladesh. Natural Hazards, 65(3), 2147-2159, https://doi.org/10.1007/s11069-012-0467-z.

Hulme, M. (2008). Geographical work at the boundaries of climate change. Transactions of the Institute of British Geographers, 32 (1), 1-8.Hulme, M., Dessai, S., Lorenzoni, I., \& Nelson, D. R. (2009). Unstable climates: Exploring the statistical and social constructions of 'normal' climate'. Geoforum, 40(2), 197-206, https:// doi.org/10.1016/j.geoforum.2008.09.010

IPCC (2012). Managing the risks of extreme events and disasters to advance climate change adaptation. A special report of Working Groups I and II of the Intergovernmental Panel on Climate Change, [C. B. Field, V. Barros, T. F. Stocker, D. Qin, D. J. Dokken, K. L. Ebi, M. D. Mastrandrea, K. J. Mach, G-K. Plattner, S. K. Allen, M. Tignor, \& P. M. Midgley (eds.)]. Cambridge University Press, UK.

Ishaya, S., \& Abaje, I. (2008). Indigenous people's perception on climate change and adaptation strategies in Jema'a local government area of Kaduna State, Nigeria. Journal of Geography and Regional Planning. 1(8), 138-143, https://doi.org/10.5897/JGRP.9000080

Jones, L., \& Boyd, E. (2011). Exploring social barriers to adaptation: Insights from Western Nepal. Global Environmental Change, 21, 1262-1274, doi:10.1016/j. gloenvcha.2011.06.002.

KC, L., Van Der Haar, G., \& Hilhorst, D. (2017). Changing gender role: Women's livelihoods, conflict and postconflict security in Nepal. Journal of Asian Security and International Affairs, 4(2), 175-195, https://doi. org/10.1177/2347797017710743.

Kitchin, R., \& Tate, N. J. (2000). Conducting research in 
Human Geography: Theory, methodology and practice. Pearson Education Limited.

Kumar, R. (1999). Research methodology: A step by step guide for beginners Sage Publication.

Lazo, J. K., Kinnell, J. C., \& Fisher, A. (2000). Expert and layperson perceptions of ecosystem risk. Risk Analysis. 20(2), 179-194, https://doi.org/10.1111/02724332.202019.

Leiserowitz, A. A. (2005). American risk perceptions: Is climate change dangerous? Risk analysis: An official publication of the Society for Risk Analysis, 25(6), 1433-1442, https://doi.org/10.1111/j.15406261.2005.00690.x.

Lindsey, L. (2005). The sociology of gender. Gender roles: A sociological perspective, Pearson Prentice Hall. $1-21$.

Manandhar, S., Vogt, D. S., Perre, S. R. \& Kazama, F. (2011). Adapting cropping systems to climate change in Nepal: a cross-regional study of farmers' perception and practices. Regional Environmental Change, 11, 335-348, https://doi.org/10.1007/s10113-010-0137-1.

McClelland, G. H. Schulze, W. D. \& Hurd, B. (1990). The effect of risk beliefs on property values: A case study of a hazardous waste site. Risk Analysis, 10(4), 485-497, https://doi.org/10.1111/j.1539-6924.1990.tb00534.x

Mersha, A. A., \& van Laerhoven, F. (2019). Gender and climate policy: a discursive institutional analysis of Ethiopia's climate resilient strategy. Regional Environmental Change, 19, 429-440, https://doi. org/10.1007/s10113-018-1413-8.

Nader, L. (1986). The subordination of women in comparative perspective. Urban Anthropology and Studies of Cultural Systems and World Economic Development, 15(3/4), 377397. Retrieved November 19, 2020, from http://www. jstor.org/stable/40553088

Nanda, P., Gautam, A., Verma, R., Hong, K.T., Puri, M., Linh, T. G., Tamang, J., \& Lamichhane, P. (2012). Study on gender, masculinity and son preference in Nepal and Vietnam. New Delhi, International Center for Research on Women.

Nepal, S. (2012). Evaluating upstream-downstream linkages of hydrological dynamics in the Himalayan Region. PhD Thesis, Friedrich Schiller University of Jena, Jena.

O’Neill, S. J., \& Hulme, M. (2009). An iconic approach for representing climate change. Global Environmental Change, 19(4), 402-410, https://doi.org/10.1016/j. gloenvcha.2009.07.004.

Oremus, W. (Feb 13, 2014). Here are all the different genders you can be on Facebook. Retrived 07 March, 2020 from: https://slate.com/technology/2014/02/ facebook-custom-gender-options-here-are-all-56custom-options.html.

Pandey, R., \& Bardsley, D. K. (2013). Human Ecological Implications of Climate Change in the Himalaya: Pilot Studies of adaptation in Agro-ecosystems within two villages from Middle Hills and Tarai, Nepal. Proceeding of Impacts World 2013, International Conference on Climate Change Effects, Potsdam, May 27-30. Available at: http://www.climate-impacts-2013. org/files/wism_pandey.pdf

Pandey, R. (2016a). Human ecological implications of climate change in the Himalaya: Investigating opportunities for adaptation in the Kaligandaki Basin, Nepal. PhD Thesis, the University of Adelaide, School of Social Sciences. Available at: http://hdl.handle. net/2440/99095

Pandey, R. (2016b). Dynamics of the Himalayan climate: A study of the Kaligandaki Basin, Nepal. Pertanika Journal of Social Sciences and Humanities (A publication of Universiti Putra Malaysia - UPM), 24(2), 737-756.

Pandey, R. (2017). Gender dimensions of climate change impacts and adaptation responses: A study of Kaligandaki Basin, Nepal. Unpublished Research Report Submitted to Pokhara University Research Centre, Pokhara University, Nepal

Pandey, R. (2019a). Male Out-Migration from the Himalaya: Implications in gender roles and household food (in)security in the Kaligandaki Basin, Nepal. Migration and Development, https://doi.org/10.1080/2 $\underline{1632324.2019 .1634313}$

Pandey, R. (2019b). To Engender or to Impede the 'Gender'? ICT in the context of Gender Equality (SDG \#5). A Conference paper presented in: T4S Conference, Kathmandu City College, Kathmandu- 27 July, 2019. Available at: https://www.researchgate.net/ publication/334736799 To Engender or to Impede the 'Gender'_ICT_in_the_context_of_GenderEquality_SDG 5 .

Rayner, S. (2003). Domesticating nature: Commentary on the anthropological study of weather and climate discourse. In S. Strauss \& B. S. Orlove (eds). Weather, Climate, Culture. Berg Publishers, 277-290.

Röhr, U. (2007). Gender, climate change and adaptation. Introduction to the gender dimensions. Background Paper prepared for the Both ENDS Briefing Paper, www.genanet.de; www.gendercc.net

Rowe, G., \& Wright, G. (2002). Differences in expert and lay judgements of risk: myth or reality? Risk Analysis, 21, 341-355, https://doi.org/10.1111/0272$\underline{4332.212116}$

Ruel, E., \& Hauser, R. M. (2013). Explaining the gender wealth gap. Demography, 50(4), 1155-1176. https:// doi.org/10.1007/s13524-012-0182-0.

Scott, J. W. (1989). Gender: A useful category of historical analysis. In A. Rao (eds.) Women's Studies International: Nairobi and beyond. The Feminist Press at City University of New York.

Shah, T., \& Lele, U. (2011). Climate change, food and water security in South Asia: Critical issues and cooperative strategies in an age of increased risk and 
uncertainty. Synthesis of Workshop Discussion. A Global Water Partnership (GWP) and International Water Management Institute (IWMI) Workshop, 23-25 February 2011, Colombo, Sri Lanka.

Spellman, G.,Field,K.,\& Sinclair,J.(2003).Aninvestigation into UK higher education student's knowledge of global climatic change. International Research in Geographical and Environmental Education, 12(1), 6-17, https://doi.org/10.1080/10382040308667509.

Stallen, P. J. M., \& Tomas, A. (1988). Public concern about industrial hazards. Risk Analysis. 8 (2), 237-245, https:// doi.org/10.1111/j.1539-6924.1988.tb01177.x

Stedman, R. C. (2004). Risk and climate change: Perceptions of key policy actors in Canada. Risk Analysis, 24(5), 1395-1406, https://doi.org/10.1111/ j.0272-4332.2004.00534.x

Sujakhu, N. M., Ranjitkar, S., He, J., Schmidt-Vogt, D., Su, Y., \& Xu, J. (2019). Assessing the livelihood vulnerability of rural indigenous households to climate changes in Central Nepal, Himalaya. Sustainability, 11, 2977; https://doi.org/10.3390/su11102977

Sundblad, E. L., Biel, A., \& Gärling, T. (2007). Cognitive and affective risk judgements related to climate change. Journal of Environmental Psychology, 27(2), 97-106, https://doi.org/10.1016/j.jenvp.2007.01.003.

The Telegraph UK (October 20, 2019). Facebooks-71gender-options-come-to-UK-users, Retrived 07 March 2020 from https://www.telegraph.co.uk/technology/ facebook/10930654/Facebooks-71-gender-optionscome-to-UK-users.html.

Turner, A. G., \& Annamalai, H. (2012). Climate change and the South Asian summer monsoon. Nature Climate Change, 2(8), 587-595, https://doi.org/10.1038/ NCLIMATE1495.

UN (2019). International Migration 2019. Population Division, www.unpopulation.org, Retrived 07 March, 2020 from https://www.un.org/en/development/desa/ population/migration/publications/wallchart/docs/ MigrationStock2019_Wallchart.pdf.

UNDP/ HDR (2019). Human Development Report 2019 Beyond income, beyond averages, beyond today: Inequalities in human development in the 21st century, UNDP.

Vetås, O. R. (2007). Global changes and its effect on glacier and cultural landscapes: Historical and future considerations. In R. P. Chaudhary, T. H. Aase, O. R. Vetås \& B. P. Subedi (eds), Local Effects of Global Changes in the Himalaya: Manang, Nepal. Tribhuwan University Nepal and the University of Bergen, Norway, pp. 23-39.

Weber, P. (February 21, 2014). Confused by all the new Facebook genders? Here's what they mean, Retrived 07 March, 2020 from https://slate.com/ human-interest/2014/02/gender-facebook-now-has56-categories-to-choose-from-including-cisgender- genderqueer-and-intersex.html.

WHO (2011). Gender, climate change and health, World Health Organisation.

Rishikesh Pandey, Ph. D. (http://orcid.org/0000-00024271-6723) is Associate Professor at Pokhara University, and currently, he is working as Director-Quality Assurance and Accreditation, University Grants Commission, Nepal since 2019. His specialized areas include Environment and Development, Geographer. He obtained a Ph. D. Degree from the University of Adelaide, Australia; and M. Phil. degree from the University of Oslo, Norway, and MA from Tribhuvan University, Nepal. He has been working in the field of Quality Assurance and Accreditation of Higher Education in Nepal, Developing educational policies and programs for the country and region. He is the Member Secretary of the Higher Education Quality Assurance and Accreditation Council, Nepal, and a Member of Nepal Medical Education Accreditation Council.

Email: itsmehimalaya@gmail.com 